\title{
The Health and Wellbeing of Gypsies and Travellers in Settled Housing: A Narrative Review of the Evidence and Policy
}

\author{
Vincent La Placa ${ }^{1} \&$ David Smith ${ }^{2}$ \\ ${ }^{1}$ Department of Psychology, Counselling and Social Work, Faculty of Education and Health, University of Greenwich, \\ Avery Hill Road, London. \\ ${ }^{2}$ Department of Psychology, Counselling and Social Work, Faculty of Education and Health, University of Greenwich, \\ Avery Hill Road, London. \\ Correspondence: Vincent La Placa, Department of Psychology, Counselling and Social Work, Faculty of Education and \\ Health, University of Greenwich, Avery Hill Road, London.
}

Received: July 5, 2016

Accepted: July 18, 2016

Available online: August 16, 2016

doi:10.11114/ijsss.v4i9.1812

URL: http://dx.doi.org/10.11114/ijsss.v4i9.1812

\begin{abstract}
Gypsies and Travellers have historically been afforded low priority in research into their health and wellbeing despite evidence of negative social and health and wellbeing experiences in daily living. This article presents a narrative review of the literature around the health and wellbeing of Gypsies and Travellers in settled housing. From the evidence, two themes emerge. The first one demonstrates that the experience of settled housing is often detrimental to the health and wellbeing of Gypsies and Travellers. The second theme suggests that Gypsies and Travellers often attempt to minimise the negative impacts of the shift into settled housing to assist in enhancing health and wellbeing. The article then proceeds to suggest how health and wellbeing researchers and social policy makers can further develop the evidence base and the policy and practices responses required as a result.
\end{abstract}

Keywords: Gypsies, Travellers, health, wellbeing, settled housing

\section{Introduction}

Gypsies and Travellers are recognised ethnic minority groups and are largely defined as persons with a tradition of nomadism, of living in extended family groupings and with distinctive economic practices including a preference for family based self-employment (Liegeois and Gheorge, 2004). They have historically been afforded low priority in research into their health and wellbeing despite their negative social experiences in daily living (Van Cleemput, 2012). Often research focuses on, for example, maternal child health, immunisation and congenital abnormalities (Carr et al., 2014). Evidence assumes forms of objectively measured causal assumptions and negates individuals' experiences, as poor outcomes are often explained with recourse to stereotypes around the health of ethnic minorities and 'blames' them for unsatisfactory lifestyles (Van Cleemput, 2012). The wider structural domains that constrain Gypsies and Travellers, and which result in negative social and health experiences, are often negated as a result (for example, discrimination in the forms of legislation, barriers to health and social care services, and other social prejudices that enhance stress).

Nevertheless, evidence strongly suggests that Gypsies and Travellers are the most excluded group across several domains such as education, housing, and are over-represented in the criminal justice system (Cemlyn et al., 2009). They experience more morbidity and lower mortality rates compared with other low socio-economic groups (Parry et al., 2004; Smith and Ruston, 2013). Whilst Gypsies and Travellers experience high levels of racism, much of which has been historically institutionalised, they are more resigned to racial hostility, rarely reporting such incidents to the authorities due to negative stereotyping and mistrust of the police (Smith and Ruston, 2013). These negative social attitudes often manifest themselves in a desire for spatial separation among the sedentary population, particularly in terms of housing. Previous research also demonstrates a convincing link between the physical environment and poor health and wellbeing outcomes of Gypsies and Travellers (Greenfields and Smith, 2010; Smith and Greenfields, 2013). This considers, for example, the internal conditions of caravan sites and the external physical and social environments in which they are located. The extent to which people feel in control over where and how they live is also significant in influencing health and wellbeing outcomes. Lack of control and ability to manage housing environments often has a crucial health-damaging effect on a marginalised social status and exacerbates existing health inequalities (Van Hout 
and Staniewicz, 2012; Ruston and Smith, 2013). The criminalisation of unauthorised camping and a decline in public site vacancies following the 1994 Criminal Justice and Public Order Act has precipitated a drift into 'conventional' and 'settled' housing over recent decades as options to live a nomadic life, or to reside on campsites, have been significantly curtailed post-1994. Around two-thirds of the UK's estimated 300,000 Gypsy and Traveller population are now resident in 'bricks and mortar' (Greenfields and Smith, 2010). As a result, this article reviews the evidence base related to the health and wellbeing of Gypsies and Travellers in settled housing, using a narrative review. It then suggests how health and wellbeing researchers and social policy makers can further develop the evidence base and the policy and practices responses required as a result.

A focus upon how Gypsies and Travellers experience the shift into settled housing, and its effects upon health and wellbeing, can be central to illustrating theoretical debates around 'power differentials', 'marginalisation' and the 'inter-dependence' of social structure and agency among health and social policy makers and researchers (Alcock, 2006; La Placa and Corlyon, 2016). Both Elias (1994) (in the theory of dis-identification) and Bourdieu $(1993,1998)$ (through the theory of habitus) have considered how the social exclusion of marginalised communities is constructed, but also resisted, through a complex interplay of power relations on the levels of structure and agency. Bourdieu's $(1993,1998)$ theory of habitus particularly focused upon how one's positions and practices were influenced by broader social environments, referred to as 'fields'. Fields are constituted through social and discursive rules, regulations and patterns that assign dominant status to some and less to others, for example, systems of law and education. Furthermore, fields operate through individual ability to alter positions, for instance, use of knowledge and resources to resist dominant discourses and produce positive outcomes and change fields of cultural interaction.

Harrison and Davis (2001) also highlight the need for social policy makers to consider how grassroots and community activities takes place within an ensemble of inter-linking structural regulatory practices, some discordant, and others shifting over time. Individuals are active agents but in contexts that privilege some and disadvantage others in regular and patterned ways (Harrison and Davis, 2001). Similarly, health and social policy makers and researchers are also critically recognising how health, and wellbeing, in particular, are inter-connected with 'place' and context and the inter-relationships of emotional, social, cultural and experiential meaning that both shape place and are shaped by it (Atkinson et al., 2012). Generally, two discernible, but inter-linked themes emerged through data analyses of the evidence base. Firstly, location to settled housing often had negative effects upon the health and wellbeing of Gypsies and Travellers in the forms of shock and trauma, coping with and management of the experience of settled housing and the loneliness and isolation which often results. Secondly, the evidence base suggested that the effects on health and wellbeing are minimised through coping strategies such as replicating former nomadic living arrangements; through the use of symbolic forms of capital, and re-construction of communities in settled housing.

\section{Methods}

Evidence was generated through an exploratory narrative review where reviewers used and synthesised various sources from which conclusions were produced into holistic interpretations, based on existing research, theories and models (Kirkevold, 1997; Popay and Mallinson, 2013). Generally, the topic under consideration was not amenable to systematic review, mainly due to the paucity of research into Gypsies and Travellers in settled housing and health and wellbeing outcomes. Reviewers produced exhaustive inclusion criteria to generate effective evidence in providing information about the health and wellbeing of Gypsies and Travellers within settled housing. The primary inclusion criteria were that research should be primarily from a credible academic perspective (i.e. not anecdotal or unpublished evidence) and that literature focused primarily on Gypsies and Travellers in settled housing and its effects upon their health and wellbeing. Research on, for example, health and wellbeing on caravan sites and 'roadsides' were excluded. To enhance the range of evidence, no cut-off date for sources was established. Relevant key search terms were drawn up and employed to guide the selection of relevant evidence. For instance, 'Gypsies and Travellers' and 'housing' were combined as search terms. Another example was the combination of the search terms, 'Gypsies' and 'physical environments'.

The search engines International Bibliography of the Social Sciences, SwetsWise and JSTOR were used to select sources. In total, 22 sources were identified through reference to the title, abstract and introduction of the relevant article/source, and occasionally, through other references, identified in an article. All sources are cited in the article. Data sources were critically appraised for relevance, usefulness and validity of findings. Themes were generated through the application of a thematic analyses and synthesis of data approach (Gibbs, 2007). Similar concepts and findings were summarised under thematic headings and tabulated to enable identification of two prominent themes after coding of data. The advantage of the narrative review was its ability to provide data in a field where very little literature exists, but where the authors possessed a considerable degree of expertise across the subject as a result of involvement in similar research into Gypsies and Travellers. 
The current evidence base is limited. Compared with settled housing, there is far more literature focused upon nomadic forms of living arrangements and its health and wellbeing outcomes. Much of it assumes a qualitative approach, based upon research with small theoretical/convenience samples. This is unsurprising given that Gypsies and Travellers often fall under the category of 'hard to reach' and are not necessarily amenable to inclusion within larger samples. Nevertheless, much of the existing literature is in-depth and rich in detail as a result, and does not seek to generalise the experiences of participants. Generally, the evidence base defined and used health in its positive sense that proceeded beyond absence of disease to encompass a broad definition which includes, for example, physical, social and psychological wellbeing (La Placa et al., 2013) but which also avoided reducing it to a purely individual phenomenon by consideration of how health and wellbeing are constructed contextually. Health and wellbeing were theorised as situational and relational as opposed to traditional explanations based upon stable and measureable categories (McNaught, 2011; La Placa and Knight, 2014a, 2014b). The literature identified concentrated mostly on British or English Gypsies (Romanichals) and Irish Travellers. Only one source, that of Berlin (2015), compared two samples: one sample comprised Roma migrants living in Finland, and another, English Gypsies/Irish Travellers living in the UK.

\section{Results}

\subsection{The Negative Health and Wellbeing Effects of Settled Housing on Gypsies and Travellers.}

Harrison and Davis (2001) highlighted the need for social policy makers and researchers to recognise that social structures and organised institutional properties are themselves built upon specifics that regulate individuals' lives and plans through specific processes, practices and ideas, similar to Bourdieu's $(1993,1998)$ concept of field. For example, structures and processes of housing often operate, and are confirmed, through dominant ideologies around housing, such as the superiority of settled communities compared with nomadic ones and which sharply differentiates the two (McVeigh, 1997). Another dominant assumption around housing is that a building should confine individuals physically and privately within one space and surrounding spaces are often perceived as out of bounds to others who do not share the given space (Berlin, 2015). Such processes and ideologies often confirm 'common sense' practices, ideas and arrangements about living in houses which form the foundations of wider institutionally arranged structures and organisations. The evidence suggested that the shift of Gypsies and Travellers into the conventional and dominant structures and practices of settled housing, has made it a critical terrain/field for them in terms of how they experience it, and how this directly or indirectly effects their health and wellbeing (Smith and Greenfields, 2014).

For many Gypsies and Travellers, the shift into settled housing constituted a coercive experience and was a significant disruption to their social environments (Crawley, 2004; Parry et al., 2004; Cemlyn et al., 2009; Staniewicz, 2009; Smith and Greenfields, 2013). The shift into, and experiences of, settled housing was often characterised by experiences of shock and trauma for Gypsies and Travellers (Smelser, 2004; Luckhurst, 2008; Greenfields, 2009). Individuals were psychologically and culturally disembedded from traditional locations, relationships and lifestyles, often invalidated by mainstream society, and experienced this as shocking and traumatic (Bonnano, 2004; Sztompka, 2004; Tatz, 2004). For instance, separation from extended kin networks and social support often exposed them to an increased risk of racism. Traumatic events and interactions left indelible impressions upon group consciousness and placed limits upon abilities to resist invalidation of group culture (Luckhurst, 2008).

Indeed, as Greenfields and Smith (2011) reported, this proceeded as far as many Gypsies and Travellers perceiving themselves as 'officially' de-racialised once not living in caravans, and located into settled housing, due to the failure of local authorities and service providers to recognise their ethnicity or to acknowledge the difficulties and needs they may have. Much of the trauma resulting from the shift into settled housing was often felt with regard to the negative effects on health and wellbeing. This was compounded by dominant ideologies that privileged sedentarism and denigrated nomadism, often resulting in increased health and social inequalities and a diminished ability to assert control over, and validation of, their social environments (Cemlyn et al., 2009; Greenfields, 2009).

Evidence suggested that the communal and kin-based structure of Gypsy and Traveller culture often conflicts with settled housing, which is largely designed for the nuclear family, exposing them to loneliness and isolation that they might not otherwise have encountered (Powell, 2008). According to Smith and Greenfields (2013), it was frequently the poorer sections of the Gypsy and Traveller community, who lacked the resources to purchase land or private housing, which located to social housing. Many participants in studies conducted by Greenfields and Smith (2010) and Smith and Greenfields (2011) claimed that their living standards had deteriorated following the move into housing due to higher living costs, which often led families into debt and enhanced stress. Particularly for families with limited literacy, the paperwork and bureaucracy involved in managing and retaining a property could be psychologically distressing, sometimes resulting in tenancies being forfeited and households returning to 'the road' or to stop with relatives on sites, precipitating further disruption (Niner, 2003; Parry et al., 2004; Power, 2004; Gidley and Rooke, 2008; Smith and Greenfields, 2013). Difficulties managing and coping with the practical, social and spatial aspects of life in 'bricks and 
mortar' were compounded by the unfamiliar physical layout of housing. Some Gypsies and Travellers found that settled housing prevented them from continuing previous living arrangements of which they had become traditionally attached to, for example, too much confinement to houses compared with caravans, and a lack of outside access to neighbours (Hodges and Cemlyn, 2013).

Berlin (2015) in interviews with Finnish Roma and Gypsies/Travellers in the UK found that the lack of an adequate garden was often difficult for participants to cope with since they lacked trust in the ability of their children to play safely in public spaces. Overcrowding was often perceived as difficult. Often participants reported that they failed to see the logic of putting people into overcrowded housing when their preference was to live on sites in caravans and chalets which did not lead to overcrowding. Participants in Smith and Greenfield's (2013) study contrasted the synthetic nature of house-dwelling with the 'natural' and 'nomadic' life and perceived the former as injurious to physical health and wellbeing, in terms of, for instance, lack of 'fresh air' and 'day light', 'lung problems' as well psychological health problems engendered by confinement to settled housing such as 'panic attacks'. Berlin (2015) also reported that whilst some Gypsies and Travellers welcomed the fact that settled housing was often warmer and contained indoor bathrooms and toilets, many experienced it as 'claustrophobic' and inimicable to the 'outdoor' life compared with caravan sites, exacerbating perceptions of its unhealthiness. For instance, individuals often found it difficult to become accustomed to using the stairs. Gypsy and Traveller women tended to report that they were accustomed to spending most of their time outside and that domestic duties were consistently interrupted by their children, who were perceived as 'trapped' indoors with them. Mothers often felt pressured to 'train' children into new ways of behaviour conducive to settled housing, for example, confinement to designated gardens and spaces of interaction. Anxiety was often exacerbated by perceptions that neighbourhoods could be unsafe if participants did not conform to the conventional expectations of sedentary housing (Emmerson and Brodie, 1987; Morran, 2002).

The literature suggested that social isolation and loneliness for Gypsies and Travellers resident in settled housing cannot be purely perceived in terms of individual psychology and behavior. Rather, it occurred often through systemic pathways tied to, for instance, socio-economic structures, racism, and neighbourhood conditions and was further interlinked with individual life-histories and local circumstances (Hofrichter, 2010). Gypsies and Travellers in settled housing could become progressively isolated and detached from others, not only due to the perceived requirement to adapt to new practices to which many are unaccustomed (Emmerson and Brodie, 1987; Thomas and Campbell, 1992; Hodges and Cemlyn, 2013), but also because of disruption to previous community relations and networks. Combined, these pressures often destabilised the fundamental make-up of Gypsy and Traveller culture and lifestyles (Smelser, 2004; Staniewicz, 2009; Thomas and Campbell, 1992). Social and spatial isolation and loneliness were acutely experienced when Gypsies and Travellers are housed in environments where they had few family and community members nearby (Staniewicz, 2009; Smith and Greenfields, 2012). Social isolation was also often intensified through hostility from neighbours and accounts of racial harassment. (Powell, 2008; Staniewicz, 2009; Smith and Greenfields, 2013). Berlin (2015) argued that even where Gypsies and Travellers assimilate into mainstream society in terms of, for example, taking up less self-employment, or re-locating to settled housing, they continued to experience discrimination, pressure to conform, and social isolation that threatened their wellbeing.

For instance, anxieties around managing behavior in neighbourhoods and adjusting to unfamiliar social and physical environments were compounded where previous social and kinship support mechanisms were perceived to have dissipated. Older Gypsies and Travellers often expressed inter-generational concerns, for example, guilt for not giving their children the same chances that they felt they had been given, for instance, to grow up with other Gypsy and Traveller children and to have the support of their whole extended kin group. Berlin (2015) also argued that the emergence of modernity, with its emphasis upon individualism, choice, and decline in traditional modes of thought of action generated intense experiences of loneliness and isolation for Gypsies and Travellers. This was compounded by their traditional adherence to collective living and the importance of community structures. As a result, Finnish Roma were characterised by a tendency to want to live 'normally' and 'live well' (as defined by dominant discourses of what is most rational and in their interest) and adapted their cultural practices towards more 'mainstream' traditions. Locating to settled housing was a means of displaying these tendencies. Similarly, as McVeigh (1997) has suggested, the emergence of the modern nation state, characterised by its permanent borders, and which subjects all citizens to one social, judicial and administrative authority also increased the ideology of sedentarism as distinctions between nomadic and settled communities intensified. The pressure on Gypsies and Travellers to integrate into settled communities was exacerbated as the nation state came to lay more claims to creating homogenous national and ethnic societies within carefully defined borders, less accessible to outsiders.

\subsection{How Gypsies and Travellers Enhance Health and Wellbeing in Settled Housing}

The second theme identified in the evidence base demonstrated that Gypsies and Travellers often attempted to minimise the negative social, health and wellbeing outcomes of settled housing and often 'resisted' mechanisms of social control 
and pressures to assimilate (Leonard, 1997; McKee, 2009; Smith and Greenfields, 2013). Leonard (1997) has coined the term the 'micro-resistance of everyday life.' The focus is upon how individuals in everyday local interactions produce and retain means of resisting social control and discursive regulation and express it through 'survival' strategies. Whilst this is different from the concept of 'collective resistance' in terms of, for instance, social movements organised around large scale social change, the evidence suggested that location into settled housing often comes to represent a 'space' of social exclusion (Gough et al., 2006) as well as further fields and sites of resistance and means to engage with alternatives to enhance health and wellbeing (Niner, 2003, 2004; Gidley and Rooke, 2008).

One adaptation strategy which emerged in the limited literature was the desire to mitigate social and spatial disorientation by replicating previous living arrangements and adapting them to current ones (Niner, 2003, 2004; Gidley and Rooke, 2008; Smith and Greenfields, 2013). For example, Smith and Greenfields (2013) found participants often slept communally in one room and made little use of the upstairs, preferring it for storage. Similarly, Berlin's (2015) participants indicated that they coped with social and physical isolation by reproducing familiar patterns of behavior such as congregating in neighbours' gardens and houses or standing outside their homes watching people go by. Often participants made a house resemble a caravan by adorning it with traditional cultural symbols: displays of bone china and cut glass, lace curtains and by leaving windows and doors open continuously to keep the temperature down to the lower degree common in trailers and enable a breeze to blow through. Outside, stone horse heads and insignia, wagon wheels and horseshoes were commonly displayed as symbols of cultural identity and resistance to assimilation.

Social, psychological and developmental studies indicate that a strong ethnic identity generally contributes positively to psychological health and wellbeing (Luckhurst, 2008; Madrigal, 2008; Hodges and Cemlyn, 2013). Powell (2008) argued that power differentials shape the social relations between Gypsies Travellers and the settled population, whom often employed stigmatisation to maintain the lower social status of the former. Despite the low social status of Gypsies and Travellers, the evidence base reported that their negative profile is contested, often through what Bourdieu (1993, 1998) termed 'symbolic capital'. This is the process through which social groups can enhance, for example, its prestige and reputation, by accentuating the value and worth of cultural symbols and behaviors attached to it. Similarly, McVeigh (1997) suggested that in spite of the pervasiveness of anti-Gypsy stereotypes, many remained convinced of their own superiority vis-à-vis settled society. Smith and Greenfields (2013) reported that one strategy for negating derogatory labelling was through the dissolution of stereotypes that associate Gypsies with dirt, crime and disorder. Rather, the application of self-referential meanings that reversed them were levelled at their 'gorjer' (or gadje, the Romani word for non-Gypsy) neighbours whose standards of cleanliness and hygiene practices were viewed as inferior to their own.

Powell (2008) referred to processes of collective identification which afforded a 'we image' among Gypsies and Travellers and a process of dis-identification from settled populations. This cohered around attitudes and practices regarding, for instance hygiene and child-rearing practices and which bolstered the collective wellbeing of the group. Through in-depth interviews and focus groups, Greenfields and Smith (2011) found that participants frequently dwelt on the strength of their Gypsy and Traveller identities as a source of strength in a hostile environment and as a way of constructing a perceived boundary in relation to perceived sedentary communities, albeit often at the expense of developing close inter-ethnic/community relationships. Greenfields and Smith (2010, 2013), in qualitative interviews with housed Gypsies and Travellers, discovered that the application of 'histories of mobility' and 'family ancestries' were significant components of individual and collective identity and wellbeing, further mobilised through the enhancement of symbolic capital. This often emphasised traditional Gypsy and Traveller living arrangements in terms of, for instance, trailers and caravans, compared with the incompatibility of settled housing practices with positive health and wellbeing outcomes.

Gypsies and Travellers also attempted to construct communities of their own to improve social and psychological wellbeing in the face of perceived hostility from settled communities (Emmerson and Brodie, 1987; Power, 2004; Powell, 2008; Smith and Greenfields, 2013; Berlin, 2015). Bourdieu (1993, 1998) also referred to 'social capital', positions and resources linked to valued social relations and support around who one knows and may assist in achieving desired goals within given contexts. The evidence suggested that Gypsies and Travellers often constituted residential enclaves through the conscious application of social capital and strategic use of for instance, the housing allocation system allowing them to exchange council/social housing and create concentrations of Gypsies and Travellers in certain streets and neighbourhoods. Greenfields and Smith $(2010,2011)$ reported that as priority for housing in a location was given to Gypsies and Travellers with existing family connections, participants often applied to be housed on estates in close proximity to family. Living in closer proximity to other Gypsies and Travellers enabled further acquisition of social capital through the ability to preserve their distinct culture and traditions more effectively.

Access to informal sources of knowledge around housing availability also enabled a significant degree of movement within housing (Powell, 2008; Smith and Greenfields, 2013). A trend of frequent movement between houses was 
identified as participants practiced a new form of nomadism within settled housing. Exchange of premises was achieved through complex networks of meticulously planned transfers until residents were able to settle closer to their family and wider support that enhanced perceived social capital. Access to social support networks was a key determinant of psychological health and wellbeing as it enhanced the security and the solidarity often experienced within nomadic environments. Evidence suggested that a focus upon social relations and the formation of spatially bounded networks were significant to comprehending the processes through which either housed Gypsies and Travellers adapt, or alternatively succumb, to the injurious effects upon health and wellbeing.

\section{Discussion}

\subsection{Research and Social Policy: Health, Wellbeing and Settled Housing}

Relations between non-sedentary groups and the state in the UK have involved a cyclical relationship, whereby the state implements laws and statutes to outlaw nomadism and fragment the groups' communal basis. Those groups subsequently devise collective strategies to evade them, often instigating a new phase of legislation. Since the 19th century, settlement and assimilation of Gypsies and Travellers and other nomadic groups, has become the preferred approach of governments. The increasing role of the state in the population's welfare has also impinged on nomadic groups as the authorities have been granted powers to take action against, for example, perceived unsanitary dwellings. This, combined with the shift towards an industrial society, fueled a drift towards towns and cities. Often this involved living in deprived inner city neighbourhoods or camping in yards in those neighbourhoods or on the large shanty towns that emerged on the urban fringes between the mid-19th and mid-20th centuries (Greenfields and Smith, 2015).

Most significantly, the 1994 Criminal Justice and Public Order Act continued this assimilatory logic in a more coercive manner by repealing the duty to provide sites, making unauthorised camping a criminal offence, and granting new police powers to break up travelling convoys and confiscate vehicles. Difficulties gaining planning permission for private sites and the criminalisation of nomadism have all contributed to increasing numbers entering conventional housing, particularly, social housing. As accommodation constitutes the primary mechanism in the implementation of broader assimilatory and often coercive policies, issues around housing have become a significant, if not the most significant, field in understanding the health inequalities and barriers to service access experienced by Gypsies and Travellers.

As recognized ethnic minority groups, Gypsies and Irish Travellers are entitled to respect for their traditional way of life, meaning that local authorities have a positive obligation to act as to facilitate the Gypsy way of life without being under a duty to guarantee it in any particular case (DCLG, 2014). Despite this, an assimilatory logic continues to underpin policy towards Gypsies and Travellers and has intensified under the current government (DCLG, 2012). It has also proposed to change the ethnic minority status of Gypsies for planning purposes, with the emphasis on proving that one travels continuously for the purposes of, not only planning, but decisions around 'appropriate' housing need. This could be construed as a strategy to reduce site demand and coerce more Gypsies and Travellers into housing, since a politically engineered shortage of sites, combined with harsh penalties for unauthorised camping, is the main reason that many have ceased travelling (Smith and Greenfields, 2013). Far from remedying the problem of accommodating Gypsies and Travellers however, assimilatory policies often heighten perceptions of a 'Gypsy problem', compounding the discrimination experienced. However, as suggested, there is a paucity of empirical knowledge around the effects of settled housing upon Gypsy and Traveller health and wellbeing. Neither is the evidence base robust enough to provide for adequately informed public health and wellbeing policies and interventions or social policies.

As a result, we argue for more empirical public health and wellbeing research to further the evidence base and fill an important gap in the knowledge of the experiences of assimilatory housing policies on Gypsies and Travellers and its impact upon their health and wellbeing. An invigorated evidence base would assist the development of more effective policy and practice, tackle health inequalities, and encourage culturally sensitive health promotion (Condon and Salmon, 2014). One means of achieving this is through qualitative research that discovers how individuals and groups negotiate and alter the terrains and fields that structure their day-to-day interactions (Savin-Baden and Howell Major, 2013; Green and Labonte, 2008; Green and Thorogood, 2014). Through the observable behavior and experiences of individuals in everyday fields, researchers are able to generate further questions and knowledge around how wider discourses and practices around health and wellbeing are utilised or challenged. Further research is also required to be more theoretically informed and critically linked to emerging empirical data. Bourdieu's $(1993,1998)$ theory of habitus that integrates structure and agency and focuses upon how one's positions and practices are influenced by broader social environments and fields may be considerably conducive to enhancing the empirical evidence base and in the provision of solid theoretical frameworks.

The drive to sedentarise Britain's nomadic population into settled housing has often deployed paternalistic and social justice arguments to support the case, arguing that permanent settlement means that Gypsies and Travellers can access 
public services available to others. However, the evidence base vigorously demonstrates that the housing situation of Gypsy and Irish Travellers in the UK is in itself a fundamental cause for a myriad of social, economic and health related-problems (Van Hout and Staniewicz, 2012). The need for housing and healthcare policies and services to adapt to differences in lifestyles, needs and experiences, is rarely questioned. Whilst we believe that there is a substantial case for revising current policies on settlement, the evidence also suggests that there is just as great a need to develop policies to address the current situation of Gypsies and Travellers in settled housing. The evidence suggests that the various determinants of health and wellbeing, as well as the opportunities to change, are likely to operate on the community level (Hubley et al., 2013) in which social groups utilise community capacity and social capital to transform and improve their positions within fields of interaction (Freire, 1972; Bourdieu, 1998). This may involve, for example, health impact assessments, initiated and developed by Gypsies and Travellers, which are specifically inclusive of issues around housing, health and wellbeing, as well as future urban and physical design, to reduce health and wellbeing inequalities.

The evidence indicates that there should not only be emphasis upon reversing the environments that precipitate inequitable health and wellbeing outcomes but to generate the environments that create such disparities before they arise. Health and social policy is required to accentuate root based as opposed to ameliorative action focused upon individual risk factors (La Placa et al., 2014). Health and wellbeing research and social policy could be further synergised by community action research with Gypsies and Travellers. Through participatory research with local communities and other agencies, community action produces data and actions to alter local environmental factors that, for example, produce health and wellbeing inequalities (Freire, 1972; Knight and La Placa, 2013). Communities are provided with the asset based skills and resources to continue and sustain research within the community. The empirical data generated can then assist in producing enabling practical social policies and actions which assist others to, for instance, develop broader social capital and asset based skills and knowledge. Furthermore, the move to localism in public health and involvement of local people in defining and designing local health and wellbeing strategies (La Placa and Corlyon, 2014) may also enable opportunities to integrate issues affecting Gypsies and Travellers into local public health and wellbeing policies (La Placa and Knight, 2014a).

Consequently, evidence also infers that there needs to be, for instance, closer co-ordination of healthcare and housing services, but which should be responsive to the health and wellbeing of Gypsies and Travellers (Van Cleemput et al., 2007). Likewise, local housing policies should have regard to proximity to other Gypsies and Travellers in the community as a means of empowerment and utilisation of symbolic and social capital. Policy should develop means of ensuring that community healthcare and housing support is accessible to Gypsies and Travellers, but recognise that health promotion services are similarly required to be flexible in bringing adequate services to Gypsy and Traveller communities. This is intrinsic to challenging ideas that traditional paradigms are capable of representing the complexity of research and public health promotion with marginalised groups without reference to wider social contexts and fields of interaction (La Placa et al., 2014) It would also encourage a more inclusive and less hierarchical approach to tackling the social, health and wellbeing inequalities experienced by many Gypsies and Travellers.

\section{Conclusion}

Gypsies and Travellers have historically been afforded low priority in research into their health and wellbeing despite evidence of negative social and health and wellbeing experiences in daily living. This article has presented a narrative review of the literature around the health and wellbeing of Gypsies and Travellers in settled housing. From the evidence, two themes emerged. The first one demonstrates that the experience of settled housing is often detrimental to the health and wellbeing of Gypsies and Travellers. The second theme suggests that Gypsies and Travellers often attempt to minimise the negative impacts of the shift into settled housing to assist in enhancing health and wellbeing. As a result, we recommend that health and wellbeing researchers and social policy makers use the data to further develop the evidence base and policy and practices responses as grounded in the data.

\section{References}

Alcock, P. (2006). Understanding poverty, 3rd edn. London: Palgrave.

Atkinson, S., Fuller, S., \& Painter, J. (2012). Wellbeing and place. Surrey: Ashgate.

Berlin, J. (2015). Assimilated individuals and segregated communities: A comparative study of housing and living related well-being of Finnish Roma and housed Gypsies and Travellers in England. Kuopio: University of Eastern Finland.

Bonnano, G. A. (2004). Loss, trauma and human resilience: Have we misunderstood the human capacity to thrive after extremely adverse events? American Psychologist, 59, 20-28. http://dx.doi.org/10.1037/0003-066X.59.1.20

Bourdieu, P. (1993). The field of cultural production (R. Johnson, Ed and Trans. New York, NY: Columbia University 
Press.

Bourdieu, P. (1998). Outline of a theory of practice. New York, NY: Cambridge University Press.

Carr, S., Lhussier, M., Forster, N., Goodall, D., Geddes, L., Pennington, M., Bancroft, A., Adams, J., \& Michie, S. (2014). Outreach programmes for health improvement of Traveller communities: A synthesis of evidence, London: National Institute for Health Research.

Cemlyn, S., Greenfields, M., Burnett, S., Matthews, Z., \& Whitwell, C. (2009). Inequalities experienced by Gypsy and Traveller communities: A review. London: Equality and Human Rights Commission.

Condon, L., \& Salmon, D. (2014) 'You likes your way, we got our own way': Gypsie and Travellers' views on infant feeding and health professional support', Health Expectations. http://dx.doi.org/10.1111/hex.12214.

Crawley, H. (2004). Moving forward: The provision of accommodation for Travellers and Gypsies. London: Institute for Public Policy Research.

Department for Communities and Local Government. (2012). Planning policy for Traveller Sites. London: DCLG.

Department for Communities and Local Government. (2014). Consultation: Planning and Travellers. London: DCLG.

Elias, N. (1994). A theoretical essay on established and outsider relations. In N. Elias, \& J. L. Scotson (Eds.), London: Sage, The established and the outsiders, 15-52.

Emmerson, A., \& Brodie, A. (2001). Housed Irish Travellers in North London. London: Gypsy and Traveller Unit Publication.

Freire, P. (1972). Pedagogy of the oppressed. Harmondsworth: Penguin.

Gibbs, G. R. (2007). Analyzing qualitative data. London: Sage.

Gidley, B., \& Rooke, A. (2008). Learning from the local: The Newtown Neighbourhood Project: Final report. London: Goldsmiths College, University of London.

Gough, J., Eisenschitz, A., \& McCulloch, A. (2006). Spaces of social exclusion. London: Routledge.

Green, J., \& Labonte, R. (2008). Introduction: From critique to engagement: Why critical public health matters. In J. Green, \& R. Labonte (Eds.), Abingdon: Routledge, Critical perspectives in public health , 1-13.

Green, J., \& Thorogood, N. (2014). Qualitative methods for health research, 3rd edn. London: Sage.

Greenfields, M. (2009). Gypsies, Travellers and accommodation: A race equality foundation briefing paper. London: Race Equality Foundation/DLGC.

Greenfields, M., \& Smith, D. (2010). Housed Gypsy/Travellers, social segregation and the reconstruction of communities. Housing Studies, 25(3), 397-412.

Greenfields, M., \& Smith, D. (2011). A question of identity: The social exclusion of housed Gypsies and Travellers. Research, Policy and Planning, 28(3), 65-78.

Greenfields, M., \& Smith, D. (2015). Nothing new under the sun: From 19th Century 'Metropolitan Gypsyries' to 21st Century Roma 'squatter camps': Gypsy camps in London and its environs, Journal of Urban History, (forthcoming).

Harrison, M., \& Davis, C. (2001). Housing, social policy and difference: Disability, ethnicity, gender and housing. Bristol: Policy Press.

Hodges, M., \& Cemlyn, S. (2013). The accommodation experiences of older Gypsies and Travellers: Personalisation of support and coalition policy. Social Policy \& Society, 12(2), 205-219.

Hofrichter, R. (2010). Tackling health inequalities: A framework for public health practice. In R. Hofrichter, \& R. Bhatia (Eds.), Oxford: Oxford University Press, Tackling health inequalities through public health practice: Theory to action, 3-57.

Hubley, J., Copeman, J., \& Woodall, J. (2012). Practical health promotion, 2nd edn. Cambridge: Polity.

Kirkevold, M. (1997). Integrative nursing research- an important strategy to further the development of nursing science and practice. Journal of Advanced Nursing, 25, 977-984. http://dx.doi.org/10.1046/j.1365-2648.1997.1997025977.x

Knight, A., \& La Placa, V. (2013). Healthy Universities; taking the University of Greenwich Healthy Universities Initiative forward', International Journal of Health Promotion and Education, 51, 41-49. http://dx.doi.org/10.1080/14635240.2012.738877 
La Placa, V., \& Corlyon, J. (2014). Social tourism and organized capitalism: Research, policy and practice. Journal of Policy Research in Tourism, Leisure and Events, 6(1), 66-79. http://dx.doi.org/10.1080/19407963.2013.833934.

La Placa, V., \& Corlyon, J. (2016). Unpacking the relationship between parenting and poverty: Theory, evidence and policy. Social Policy and Society, 15(1), 11-28. http://dx.doi.org/10.1017/S1474746415000111

La Placa, V., \& Knight, A. (2014a). Wellbeing: Its influence and local impact on public health. Public Health, 128(1), 38-42. http://dx.doi.org/10.1016/j.puhe.2013.09.017

La Placa, V., \& Knight, A. (2014b). Wellbeing: a new policy phenomenon? In A. Knight, V. La Placa, \& A. McNaught (Eds.), Wellbeing: policy and practice, 17-27

La Placa, V., McNaught, A., \& Knight, A. (2013). Discourse on wellbeing in research and practice, International Journal of Wellbeing, 3(1), 116-125. http://dx.doi.org/10.5502/ijw.v3i1.7

La Placa, V., McVey, D., Mac Gregor, E., Smith, A., \& Scott, M. (2014). The contribution of qualitative research to the Healthy Foundations life-stage segmentation. Critical Public Health, 24(3), 266-282. http://dx.doi.org/10.1080/09581596.2013.797068

Leonard, P. (1997). Postmodern welfare. London: Sage.

Liegeois, J. P., \& Gheorge, N. (2004). Roma, Gypsies, Travellers. Strasbourg: Council of Europe.

Luckhurst, R. (2008). The trauma question. New York, NY: Routledge.

Madrigal, C. R. (2008). Acculturation, ethnic identity, resilience, self esteem and general wellbeing: A psychosocial study of Colombians in the United States. Ann Arbor: ProQuest LLC.

McKee, K. (2009). Post Foucauldian governmentality: What does it offer social policy analysis? Critical Social Policy, 29(3), 465-486. http://dx.doi.org/10.1177/0261018309105180

McNaught, A. (2011). Defining wellbeing. In A. Knight, A. \& A. McNaught (Eds.), Banbury: Lantern, Understanding wellbeing:An introduction for students and practitioners of health and social care, 7-23.

McVeigh, R. (1997). Theorising sedentarism: the roots of anti-nomadism. In T. Acton (Ed.), Hertford: University of Hertford Press. Gypsy politics and Traveller identity, 7-26.

Morran, D. (2002). Negotiating marginalized identities: Social workers and settled travelling people in Scotland. International Social Work, 45(3), 337-351. http://dx.doi.org/10.1177/0261018309105180

Niner, P. (2003). Local authority Gypsy/Traveller sites in England. London: ODPM.

Niner, P. (2004). Accommodating nomadism? An examination of accommodation options for Gypsies and Travellers in England. Housing Studies, 19(2), 41-159.

Parry, G., Van Cleemput, P., Peters, J., Moore, J., Walters, S., Thomas, K., \& Cooper, C. (2004). The health status of Gypsies and Travellers in England. Sheffield: University of Sheffield.

Popay, J., \& Mallinson, S. (2013). Qualitative research review and synthesis. In I. Bourgeault, R. Dingwall, \& R. de Vries (Eds.), London: Sage, The Sage Handbook of qualitative research methods in health research, 289-307.

Powell, C. (2008). Understanding the stigmatization of Gypsies: Power and the dialectics of (dis)identification. Housing, Theory and Society, 25(2), 87-109. http://dx.doi.org/10.1080/14036090701657462

Power, C. (2004). Room to Roam: England's Irish Travellers. London: Brent Irish Advisory Service.

Ruston, A. M., \& Smith, D. M. (2013). Gypsies/Travellers and health: risk categorization versus being 'at risk'. Health, Risk \& Society, 15(2), 176-193.

Savin-Baden, M., \& Howell, M. C. (2013). Qualitative research: The essential guide to theory and practice. London: Routledge.

Smelser, N. (2004). Psychological and cultural trauma. In J. C. Alexander, R. Eyerman, B. Giesen, N. Smelser \& P. Sztompka (Eds.), Berkeley: University of California Press. Cultural trauma and collective identity, 31-59.

Smith, D. M., \& Greenfields, M. (2012). Housed Gypsies and Travellers in the UK: Work, exclusion and adaptation. Race and Class, 53(3), 48-65. http://dx.doi.org/10.1177/0306396811425985

Smith, D. M., \& Greenfields, M. (2013). Gypsies and Travellers in housing: The decline of Nomadism. Bristol: Policy Press.

Smith, D. M., \& Greenfields, M. (2014). The wellbeing of Gypsies and Travellers. In A. Knight, V. La Placa \& A. McNaught (Eds.), Banbury: Lantern. Wellbeing: Policy and practice, 51-63. 
Smith, D., \& Ruston, A. M. (2013). 'If you feel that nobody wants you you'll withdraw into your own': Gypsy/Travellers, networks and health care utilization. Sociology of Health and Illness, 35(8), 1196-1210. http://dx.doi.org/10.1111/1467-9566.12029

Staniewicz, T. (2009). RAXEN thematic study-housing conditions of Roma and Travellers. Warwick: CRED/University of Warwick.

Sztompka, P. (2004). The trauma of social change: A case of postcommunist societies. In J. C. Alexander, R. Eyerman, B. Giesen, N. J. Smelser \& P. Sztompka (Eds.), Berkeley: University of California Press. Cultural trauma and collective identity, 155-195.

Tatz, C. (2004). Aboriginal, Maori and Inuit youth suicide: Avenues to alleviation? Australian Aboriginal Studies, 2, $15-25$.

Thomas, P. A., \& Campbell, S. (1992). Housing Gypsies. Cardiff: Traveller Law Research Unit.

Van Hout, M. C., \& Staniewicz, T. (2012). Roma and Irish Traveller housing and health: A public health concern. Critical Public Health, 22(2), 193-207.

VanCleemput, P. (2012). Gypsy and Traveller health. In J. Richardson \& A. Ryder (Eds.), Bristol: Policy Press. Gypsies and Travellers: Empowerment and inclusion in British society, 43-61.

VanCleemput, P., Thomas, K., Parry, G., Peters, J., \& Cooper, C. (2007). 'The health-related beliefs and experience of Gypsies and Travellers: A qualitative study. Journal of Epidemiology \& Community Health, 61, 205-210.

\section{(cc) $\mathrm{BY}$}

This work is licensed under a Creative Commons Attribution 3.0 License. 